\title{
Effect of Magnetic Water on Semen Evaluation and Some Hatchability Traits for Egyptian Developed Chickens
}

\author{
Hanan Hassan Ghanem*, Amany Adel El-Sahn, Osama Mahmoud Aly, Hassan Abd-El-halim \\ Animal Production Research Institute, Ministry of Agriculture, Giza, Egypt \\ Email address: \\ hananhasen2003@yahoo.com (H. H. Ghanem) \\ ${ }^{*}$ Corresponding author

\section{To cite this article:} \\ Hanan Hassan Ghanem, Amany Adel El-Sahn, Osama Mahmoud Aly, Hassan Abd-El-halim. Effect of Magnetic Water on Semen Evaluation \\ and Some Hatchability Traits for Egyptian Developed Chickens. International Journal of Animal Science and Technology. \\ Vol. 4, No. 4, 2020, pp. 81-89. doi: 10.11648/j.ijast.20200404.13
}

Received: November 17, 2020; Accepted: December 10, 2020; Published: December 22, 2020

\begin{abstract}
A total of 280 females with 28 males for Silver Sabahia strain at two different ages ( 35 and 50 weeks) were used in this study. Besides, 40 cocks (10 cocks / group) used for semen evaluation. Birds of each age were divided into two groups, the $1^{\text {st }}$ group drank water exposed to magnetic field (MFW) and the $2^{\text {nd }}$ group drank non-magnetic tap water (TW) to determine the beneficial effect of drinking magnetized water for aged chickens to cope low fertility $\%$ and hatchability $\%$, besides studying semen and egg parameters, embryonic development and chick quality. Supplementation elder cocks with MFW significantly increased semen volume, number of motile sperm and number of live sperm compared with those for untreated cocks. Treated old flock with magnetic water had a heavier egg weight $(\mathrm{p} \leq 0.05)$ than treated young flock with magnetic water. MFW X old and MFW X young had a comparable influence on egg weight loss, embryonic mortality, fertility\% and hatchability\%. On day 14 and 18 of incubation, supplementation older birds with MFW water had a heavier residual yolk sac weight $\%$ compared with the other rest groups. At hatch, the residual yolk sac weight $\%$ was similar between MFW X old and MFW X young. In addition, chick weight and all internal organs weight $\%$ were not affected by interaction of both types of water and hens age. It is concluded that exposing water to magnetic field, have a stimulating influence on the percentages of fertility and hatchability of birds (especially older age) through improving semen and egg qualities, besides stimulating the development of embryogenesis.
\end{abstract}

Keywords: Magnetic Water, Flock Age, Semen, Egg Quality, Hatching Traits, Silver Sabahia

\section{Introduction}

Age has an adverse effect on the reproductive success of birds. Many investigators detected that cocks age have a direct influence on semen quality, because concentration, motility and viability rates of spermatozoa are reduced by age [1]. Also, some studies showed that the efficiency of hens reproduction decreased with age, because it is related to the quality of hatching egg such as the internal egg composition or ratio, larger egg weight, poorer shell quality, increased early and late embryo mortality and other problems sole to large eggs from old broiler breeders [2-4].

Breeder age affects the absorption and utilization of nutrient from the yolk sac by the embryo [5], embryonic mortalities [6], hatchability\%, and chick quality [7].

Magnetized water is one of treatment that has improved the properties of water [8]. The scientific basis for the magnetic technology is a result of the physics of interaction between a magnetic field and a moving electric charge [9]. The mineral content of water can be affected by treated water with magnetic field and its effects depend on the strength of magnetic field and exposure time [10]. Nowadays, the use of magnets to improve water quality is of significant interest due to low cost compared to chemical and physical treatment [9]. Several studies indicate that magnatic fields have influence on cellular mechanism development and growth especially in the reproductive system [11, 12]. Magnetic water increased testosterone hormone and semen quality of birds [13, 14]. For hens, as a result of increasing shell thickness and weight by drinking magnetized water, eggshell quality enhanced but had no effects on egg yield or weight $[15,16]$. 
This study was conducted to determine the beneficial effect of drinking magnetized water for aged chickens to cope low fertility $\%$ and hatchability $\%$, besides studying semen and egg parameters, embryonic development and chick quality.

\section{Material and Methods}

\subsection{Experiment Design}

The experiment was conducted with 2 breeder flock age (35wk and 52wk) and 2 treated groups of water (magnetic water of 14000 Gauss (MFW) and tap water (TW)), 7 replicates were used per treatment, resulting 28 experimental units at the beginning of the study. This study was conducted at El-Sabahia Poultry Research Station, Alexandria, Animal Production Research Institute, Agriculture Research Center, Egypt.

A total of 280 females with 28 males for Silver Sabahia strain [17] were used in this study. Birds of each treatment were housed in floor pens; sex ratio comprised 1 male for 10 females for each pen. The breeder flocks received a layer breeder diet with $2800 \mathrm{ME} \mathrm{Kcal} / \mathrm{Kg}$ and $16 \%$ crud protein, diet according to the recommendation of Animal Production Research Institute (Table 1). The chemical composition of two water types was done twice one at the initiation of the experiment and the other at the end of the experiment and is shown in Table 2. Water was exposed to a magnetic field by a permanent magnet in a compact form using a unit called Delta water (Company for magnetic water softeners and Conditioners, Egypt, Figure 1). This is coaxial permanent system equipment that produced magnetic field strength as high as 14000Gauss. The strength of the magnet was measured by a gauss meter before the initiation and after the termination of the experiment. This measurement and that for chemical composition of water was done at Application Laboratory, City for Scientific Research and Biotechnology and Egypt-Japan University of Science and Technology, Egypt.

Feed and water were provided ad-libtum. Birds subjected to 16 hours light and 8 hours dark during the experimental period.

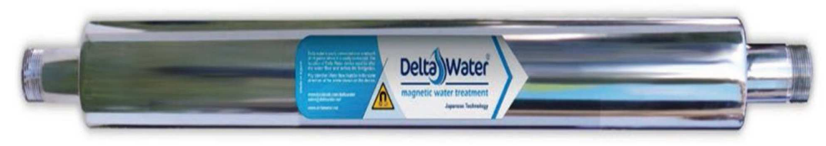

Figure 1. Magnetic device was used in this study (Delta water 14000 gauss).

\subsection{Measurements}

\subsubsection{Semen Evaluation}

At 45 weeks of age for younger cocks and 60 weeks of age for older cocks, 40 cocks (10 cocks / group) were used to evaluate semen quality. Semen samples were collected from cocks of each group once weekly by abdominal massage technique. Some semen physical properties such as ejaculate volume $(\mathrm{ml})$, sperm forward motility (\%) and live, dead and abnormal sperms (\%) were determined. Also, sperm concentration was measured by using a haemocytometer according to the procedure described by [18]. Number of motile sperm was determined by multiplying percentage of forward motility by sperm output. Also, number of live sperm was determined by multiplying percentage of live sperm by sperm output.

\subsubsection{Egg Composition}

At 43 weeks of age for younger hens and 58 weeks for elder hens, three eggs from each replicated were randomly chosen for egg quality investigation. Egg shape index was calculated as the percentage of the greatest width to the greatest length. The shell was weighed with its membranes to nearest $0.1 \mathrm{~g}$. shell with membranes thickness was measured by a micrometer to the nearest $0.01 \mathrm{~mm}$. yolk and albumen percentages were calculated relative to egg weight. The thick albumen height was measured by tripod micrometer to the nearest $0.01 \mathrm{~mm}$.

\subsubsection{Hatching Traits}

Total of 4200 hatching eggs (700 hatching eggs $\times 3$ hatch $\times 2$ age) representing the experimental treats were numbered and weighted individually prior to the beginning of incubation and incubated in Egyptian made incubation at 99.5 $\mathrm{F}$ and 55\% RH during setting phase of incubation then transferred to hatchers and incubated at $99 \mathrm{~F}$ and $70 \% \mathrm{RH}$.

At 18 day of incubation, all eggs were individually weighed $(\mathrm{g})$, the percentage of egg weight loss was calculated during the setting phase of incubation (0-18 days). Eggs were candled and those with evidence of living embryos were transferred to the hatcher with the same experimental design. The infertile clear eggs were macroscopically evaluated to determine apparent infertility by naked eyes. Fertility\% was estimated as a percentage of fertile eggs from total eggs set. Hatchability of total eggs was estimated as a percentage of sound chicks out of the total eggs set. Hatchability of fertile eggs was estimated as a percentage of sound chicks out of the fertile eggs. Eggs that failed to hatch at the end of incubation and having full opportunity for hatch were broken out and then examined with neked eye to estimate embryonic mortality during intervals (early) 1-7, (mid) 8-14 and (late) 15-21.

At days 14 and 18 during incubation, eight eggs chosen randomly from each experimental group (total 32 eggs) were weighed and opened then the embryos were separated from the remaining egg contents. Embryos were rinsed in saline and blotted dry on an absorbent paper to remove excess moisture. The dried embryos were allowed to room temperature and then weighed to the nearest $0.001 \mathrm{~g}$. Also, Residual yolk weight was expressed as percentage of embryo weight. Then, egg shell weight and thickness were determined for the same eggs and in the same days of incubation. At hatch, three hatched chicks from each replicate were weighed and slaughtered. Abdominal cavity was opened. Residual yolk sac, hearts, stomatch, fabricious gland, liver and intense were expressed as percentages of chick weight.. Also, chick length was measured from the tip 
of the beak to the end of the middle toe with the chick's dorsal surface extended over a ruler.

\subsubsection{Statistic Analysis}

Data of all studied traits were analyzed using fixed models [19] using the following model

$$
\mathrm{Y}_{\mathrm{ijk}}=\mu+\mathrm{T}_{\mathrm{i}}+\mathrm{A}_{\mathrm{j}}+\left(\mathrm{TA} \mathrm{A}_{\mathrm{ij}}\right)+\mathrm{e}_{\mathrm{ijk}}
$$

Where:

$Y_{\mathrm{ijk}}$ : an observation, $\mu$ : overall, $T_{\mathrm{i}}$ : effect of treatment, $A_{\mathrm{j}}$ : effect of age, $\left(\mathrm{TA}_{\mathrm{ij}}\right)$ : interaction between the main effect, $\mathrm{e}_{\mathrm{ijk}}$ : the residual effect. Significant differences among mean were tested using Duncan's Multiple Range test [20].

\section{Results and Discussion}

\subsection{Water Analyses}

Analyses of water used in this studied was clarified in Table 2 . In brief, water quality was found to be considerably different between tap water and magnetic water. In our research observed that magnetic water had better quality than tap water with respect to $\mathrm{pH}$, conductivity, salinity, dissolved oxygen, sodium, potassium, calcium, magnesium, chloride and carbonate bicarbonate.

\subsection{Semen Evaluation}

Effect of magnetic treatment, flock age and their interactions on semen quality of Silver Sabahia cocks are shown in Table 3. Regarding the effect of cocks age on the previous mentioned parameters, sperm concentration sperm motility $\%$, abnormal sperm, sperm output, number of motile sperm and number of live sperm were improved $(p \leq 0.05)$ for semen produced from younger age compared with older age.. It can be observed that most of semen parameters produced from cocks treated with MFW recorded the higher significant value compared with those for control ones. Interaction between experimental treatment and flock age reveals that supplementation elder cocks with MFW significantly increased semen volume, number of motile sperm and number of live sperm compared with those for untreated elder cocks. Whereas, no significant differences were observed in all semen parameters between younger cocks treated with MFW and untreated younger cocks. Moreover, the MFW X old and TW X young had a comparable semen evaluation.

Our results are in accordance with the previous research reported by (1) who found that concentration, motility and viability rates of spermatozoa reduced by the age.

It can be seen from data that treated any given age with MFW (MFW X young and MFW X old) had a comparable improve of semen parameters compared with untreated older age. This may be due to exposure of water to magnetic field can accelerate ordinary diffusion of water to penetrate the cellular wall of different body organs [21, 22]. This leads to improving the fluidity and dissolving capability of minerals and vitamins [23]. So, MFW can increase ability of body for production general and sexual hormones, transport of food in blood, and in turn improved semen characteristics [10]. Reference [14] concluded that magnetizing water improved reproductive traits and semen quality. Reference [24] reported that treated older cocks with magnetic water improved semen parameters compared with untreated ones.

\subsection{Egg Composition}

Data of Table 4 display the effect of MFW treatment, breeder age and their interactions on some parameters of egg quality for Silver Sabahia strain. Egg shape index, albumen weight $\%$ and shell thickness of older hens were similar to those of younger hens $(\mathrm{p} \leq 0.01)$, while older hens had larger egg weight, more yolk weight $\%$ and lower both of albumen height and $\mathrm{HU}(\mathrm{p} \leq 0.05)$. Regardless of age, different types of water had a significant effect only on the albumen height, shell thickness and HU, however, there was no significant effect on other egg quality. The albumen height and HU were higher in the MFW (9.42 and 98.04, respectively) than those in the TW groups (7.36\% and 89.74 , respectively). The egg weight and albumen high were influenced by the interaction between flock age and magnetized water. The both groups of the older flock had a heavier egg weight $(p \leq 0.05)$ than TW groups of the young flock, whereas the TW X old and MFW $\mathrm{X}$ young had a comparable egg weight. Albumen height and HU were the lowest $(p \leq 0.05)$ for older group treated with tap water compared to the rest groups. But there was no statistical difference in albumen height and HU between MFW X young and MFW X old. Egg shape index, Yolk weight $\%$, albumen weight $\%$, shell weight $\%$ and shell thickness were not statically influenced among all interactions. Our data are agreement with [25] who reported that egg weight increases with hen age advanced. Moreover, [26] found that the percent of yolk differ significantly between different ages and as the age advances the yolk weight increase in the egg. In addition, Rayan 2018 pointed that the egg shell weight, albumen high and HU were significantly decreased in a stepwise manner with increased parental age. Thicker egg shell in eggs from MFW groups could be derived from the fact that magnetization water is able to increase the solubility of calcium which can improve the egg shell thickness [16]. Also, [12] found that the improvement of egg shell thickness of hens offered MFW coincided with the increased in blood $\mathrm{PH}$ towards alkalinity which favorable for $\mathrm{Ca}$ deposition in shell gland and this may be due to improve metabolism of mineral for eggshell formation. In this study, the effect of type's water on egg weight is partly interred related with effect of breeder age. In both age, the improvement of HU in eggs produced from hens treated with MFW compared with group treated with tap water could be related to the change in the egg mineral contents. This explanation is confirmed by [16] who found that high $\mathrm{HU} \%$ of eggs for MFW group may be due to the change in sulfur which play a role in changing the nature of the albumen proteins. 


\subsection{Hatching Traits}

Table 5 shows that younger birds of Silver Sabahia strain recorded lower total embryonic mortalities $(\mathrm{P} \leq 0.05)$ and a higher significant fertility $\%$ and hatchability $\%$ of total eggs compared with elder one. With respect to MFW treatment, birds' drunken magnetic water recorded the higher significant fertility $\%$ and hatchability $\%$ for both of fertile and total eggs compared with control one.

No significant interaction between magnetic treatment and breed age was found for egg weight loss. The lowest significant value of interaction for fertility $\%$ was detected for TW X old compared to the rest groups. Old treated birds with MFW had a significant decreased of total embryonic mortality for setting and hatching phases than did non-treated. Younger birds followed the same statistical trend. This decrease of embryonic mortality had been reflected on the increase hatchability\% of total eggs. Moreover, MFW X old and MFW X young had a counterpale influence on all previously mentioned parameters. Numerically, hatchability of fertile eggs $\%$ for both ages followed the same trend.

Our data is coincided by [7] who recognized that fertility $\%$ decreased with age. It seems that the improve in the quality of magnetized water (Table 2) could be the reason of fertility\% increase (Table 5). These results are confirmed by [13] who reported that MFW can improve the circulation of blood and oxygen in body and in turn increase the ability of the body to produce hormones like sexual [27]. Also, our data are documented by [24] who reported that drank elder birds magnetic water significantly improved fertility $\%$ compared to untreated older group. Moreover, the results of significant increase of hatchability $\%$ for eggs of younger flock age compared to elder one are coincided with the result of [28] and could be related to the decrease of embryonic mortality. It can be seen from data that treated any given age with MFW (MFW $\mathrm{X}$ young and MFW X old) had a comparable hatchability\% of total eggs, even, when the hatchability $\%$ of untreated hens was significantly different $(77.21 \%$ vs $72.55 \%$ for 43 and $58 w k$ respectively). This may be due to MFW can improve the water properties (table 2), which consequently improves egg qualities, decreases embryonic mortalities and in turn improves hatchability\%. Our data is confirmed by [29] who found that MFW increased mineral solubility, facilitating nutrient transfer across cell membranes which in turn improved fertility and hatchability percentages.

\subsection{Embryonic Development and Chick Quality}

Table 6 demonstrates the effect of MFW, breeder age and their interactions on body weight and residual yolk sac weight $\%$ for embryos at 14 and 18 day of incubation and for baby chicks and length at hatch. At 14 and 18 day of incubation, residual yolk sac\% had been significantly (P 0.05) increased for eggs produced from older hens compared with those for younger ones. However, this significant disappeared at hatch. Regardless of flock age, during 14 to 21 $\mathrm{d}$ of incubation, the percentages of residual yolk sac weights in eggs produced from hens supplemented with magnetized water were less than those from hens drank tap water. As can be seen from these data that there is a significant interaction between breeder flock age and magnetic treatment for residual yolk sac weight $\%$ from 14 day to hatching $(\mathrm{p} \leq 0.05)$. On these days, supplementation older birds with tap water had a heavier residual yolk sac weight $\%$ compared with the other rest groups. At hatch, the residual yolk sac weight $\%$ was similar between MFW X old and MFW X young. In addition, hatched chick weight and length were significantly affected by types water and increased significantly over time, although no significant difference was found for interaction of these 2 factors. It seems that the significant decrease in residual yolk sac\% for eggs produced from older age treated with MFW in the current study could be the reason of chick weight increase at hatch $(39.33 \mathrm{gm})$ compared with those for untreated old group (36. 88gm). Moreover, the increase of hatched chicks weight which caused by treated older hens with the application of MFW could be indicated that the yolk utilization during incubation was higher than untreated older hens, resulting in fasting metabolic process and accelerate the consumption of carbohydrate and fats in yolk sac. Supporting to results and interpretation herein $[30,31]$ who mentioned that the increase in metabolic rate may be induce better and more efficient degradation of the yolk sac by the embryo. Also, [32] concluded that magnetization of water improves the water properties, which consequently improves the growth rate. [24] found that magnetizing water significantly increase yolk sac absorption and this was reflected on improve chick weight.

\subsection{Egg Shell Weight and Thickness During Incubation}

At 14 day of incubation, eggs produced from younger hens had a higher significant egg shell weight compared with older one (Table 7). Moreover, at the same age, the birds that were provided MFW had a significant thinner egg shell than did the other groups. However, these significant disappeared at the later stage of incubation (18d). Table 7 indicated that there was no significant interaction between MFW and breeder age for Silver Sabahia strain on egg shell weight and thickness at $14 \mathrm{~d}$ and $18 \mathrm{~d}$ of incubation. [24] Mentioned that treated hens ( $50 \mathrm{wk}$ or $35 \mathrm{wk}$ ) with MFW had no significant effect on eggshell weight during incubation.

\subsection{Internal Organs}

All traits of internal organs weight $\%$ were not affected by interaction of both types of water and hens age, and only the heart weight $\%$ was affected by the types of water $(\mathrm{p} \leq 0.05)$. As evidenced by other studies, magnetic water had no effect on the relative weight of stomach, fabricious, liver and intensts [24]. In addition, the increase of heart weight for chicks originating from hens received magnetic water may be indicated an adaptation to change cardiac out put to meat the demands of increased basal metabolic rate [33].

It is concluded that exposing water to magnetic field, have a stimulating influence on the percentages of fertility and hatchability of birds (especially older age) through improving 
semen and egg qualities, besides stimulating the development of embryogenesis.

Table 1. Composition and the nutritive value of the basal diets.

\begin{tabular}{ll}
\hline Ingredients & \% \\
\hline Yellow corn & 66.33 \\
Soybean meal (44\%) & 24.2 \\
Dicalcium phosphate & 1.32 \\
Limestone & 7.50 \\
Salt (Nacl) & 0.25 \\
DL - methionine & 0.15 \\
Vit\& Min mix.* & 0.25 \\
Total & 100.00 \\
Calculated analysis: & \\
Metabolizable energy (Kcal/kg) & 2777 \\
Crude protein \% & 16.97 \\
Calcium \% & 3.1 \\
Available phosphate \% & 0.37 \\
Methionine \% cyctine \% & 0.67 \\
Lysine \% & 0.8 \\
\hline
\end{tabular}

* Composition of premix in 3 kg is: Vit. A, 10.000 IU; Vit. D3, 2.000 IU; Vit E, 10.000 mg; Vit. K3, 1.000 mg; Vit. B1, 1 mg; Vit. B2, 4 mg; Vit B6, 1.5 mg; Vit. B12, $10 \mathrm{mcg}$; Niacin, $20.000 \mathrm{mg}$; Pantothenic acid $10.000 \mathrm{mg}$; Folic acid, $1 \mathrm{mg}$; Biotin, $50 \mathrm{mg}$; Choline chloride, $500 \mathrm{mg}$; Copper, $4 \mathrm{mg}$; Iron, $30 \mathrm{mg}$; Manganese, $40.000 \mathrm{mg}$; Zinc, $45.000 \mathrm{mg}$; Cu, $3.000 \mathrm{mg}$; Iodine, $300 \mu \mathrm{g}$; Selenium, $0.1 \mathrm{mg}$; Cobalt, $0.1 \mathrm{mg}$, carriercaco 3 add to $3 \mathrm{Kg}$.

Table 2. Analysis of water types used in the experiment*.

\begin{tabular}{llll}
\hline \multirow{2}{*}{ Parameters } & Unit & Tap water & Magnetized \\
\cline { 4 - 4 } & & Unmagnified & 7.10 \\
\hline PH & - & 6.83 & 736 \\
Conductivity & $\mathrm{Ms} / \mathrm{Cm}$ & 693 & 390 \\
Salinity & $\mathrm{Mg} / \mathrm{L}$ & 360 & 7.3 \\
Dissolved Oxygen & $\mathrm{ppm}$ & 6.5 & 7.1 \\
Sodium $\left(\mathrm{Na}^{+}\right)$ & $\mathrm{ppm}$ & 6.3 & 1.8 \\
Potassium $\left(\mathrm{K}^{+}\right)$ & $\mathrm{ppm}$ & 1.4 & 17.5 \\
Calcium $\left(\mathrm{Ca}^{2+}\right)$ & $\mathrm{ppm}$ & 16.7 & 5.4 \\
Magnesium $\left(\mathrm{Mg}^{2+}\right)$ & $\mathrm{ppm}$ & 4.6 & 3.1 \\
Chloride $\left(\mathrm{Cl}^{-}\right)$ & $\mathrm{ppm}$ & 2.9 & 4.1 \\
Carbonate $\left(\mathrm{CO}_{3}^{-}\right)$ & $\mathrm{ppm}$ & 3.8 & 25.6 \\
Bicarbonate $\left(\mathrm{HCO}_{3}^{-}\right)$ & $\mathrm{ppm}$ & 24.1 & 41 \\
Organic matter & $\mathrm{ppm}$ & 50 & \\
\hline
\end{tabular}

* Analyzed water at laboratory of Egypt- Japan University of Science and Technology, Alexandria, Egypt

Table 3. Effect of magnetic water treatment, flock age and their interactions on semen quality traits of Silver Sabahia strain.

\begin{tabular}{|c|c|c|c|c|c|}
\hline \multirow[b]{2}{*}{ Main effect } & \multicolumn{5}{|l|}{ Semen parameters } \\
\hline & $\begin{array}{l}\text { Ejaculate volume } \\
\text { (ml) }\end{array}$ & $\begin{array}{l}\text { Sperm concentration } \\
\left(\times 10^{8} / \mathrm{ml}\right)\end{array}$ & $\begin{array}{l}\text { Sperm forward Motility } \\
(\%)\end{array}$ & Live sperm (\%) & Dead sperm (\%) \\
\hline \multicolumn{6}{|l|}{ Type of water } \\
\hline Tap water (TW) & $0.35 \pm 0.03 \mathrm{~b}$ & $2.21 \pm 0.17$ & $85.8 \pm 1.70 \mathrm{~b}$ & $93.20 \pm 1.36$ & $3.70 \pm 0.76$ \\
\hline Magnetic water (MFW) & $0.50 \pm 0.05 \mathrm{a}$ & $2.54 \pm 0.12$ & $91.67 \pm 1.62 \mathrm{a}$ & $95.92 \pm 0.78$ & $2.15 \pm 0.36$ \\
\hline $\mathrm{Sig}$ & $*$ & Ns & $*$ & Ns & $*$ \\
\hline \multicolumn{6}{|l|}{ Flock age } \\
\hline Old 50 wk & $0.41 \pm 0.06$ & $2.19 \pm 0.14 b$ & $87.73 \pm 1.95$ & $93.58 \pm 1.27$ & $3.42 \pm 0.62$ \\
\hline Young $35 \mathrm{wk}$ & $0.44 \pm 0.04$ & $2.58 \pm 0.13 \mathrm{a}$ & $90.27 \pm 176$ & $96.00 \pm 0.71$ & $2.18 \pm 0.48$ \\
\hline Sig & Ns & $*$ & Ns & Ns & Ns \\
\hline \multicolumn{6}{|l|}{ Interaction } \\
\hline $\mathrm{TW} \times$ old & $0.30 \pm 0.04 \mathrm{~b}$ & $2.06 \pm 0.26 \mathrm{~b}$ & $84.40 \pm 2.99 \mathrm{~b}$ & $91.60 \pm 2.25$ & $4.40 \pm 1.20 \mathrm{a}$ \\
\hline $\mathrm{TW} \times$ young & $0.39 \pm 0.03 \mathrm{ab}$ & $2.35 \pm 0.21 \mathrm{ab}$ & $87.20 \pm 1.77 \mathrm{ab}$ & $94.80 \pm 1.39$ & $3.00 \pm 0.95 \mathrm{ab}$ \\
\hline MFW $\times$ old & $0.52 \pm 0.09 \mathrm{a}$ & $2.30 \pm 0.16 \mathrm{ab}$ & $90.50 \pm 2.14 \mathrm{ab}$ & $95.00 \pm 1.36$ & $2.71 \pm 0.56 \mathrm{ab}$ \\
\hline MFW $\times$ young & $0.48 \pm 0.07 \mathrm{ab}$ & $2.78 \pm 0.12 \mathrm{a}$ & $92.80 \pm 2.52 \mathrm{a}$ & $97.00 \pm 0.37$ & $1.50 \pm 0.22 \mathrm{~b}$ \\
\hline Sig & $*$ & $*$ & $*$ & Ns & $*$ \\
\hline
\end{tabular}


Table 3. Continued.

\begin{tabular}{|c|c|c|c|c|}
\hline \multirow[b]{2}{*}{ Main effect } & \multicolumn{4}{|l|}{ Semen parameters } \\
\hline & $\begin{array}{l}\text { abnormal sperm } \\
(\%)\end{array}$ & $\begin{array}{l}\text { Sperm output } \\
\left(\left(\times 10^{8} / \text { ejaculate }\right)\right.\end{array}$ & $\begin{array}{l}\text { Number of motile sperm } \\
\left(\times 10^{8} / \text { ejaculate }\right)\end{array}$ & $\begin{array}{l}\text { Number of live sperm } \\
\left(\times 10^{8} / \text { ejaculate }\right)\end{array}$ \\
\hline \multicolumn{5}{|l|}{ Type of water } \\
\hline Tap water (TW) & $3.1 \pm 0.66$ & $0.78 \pm 0.10 \mathrm{~b}$ & $67.25 \pm 9.94 a$ & $72.89 \pm 10.45$ \\
\hline Magnetic water (MFW) & $1.92 \pm 0.47$ & $1.24 \pm 0.14 \mathrm{a}$ & $112.49 \pm 11.5$ & $119.29 \pm 12.51$ \\
\hline Sig & $*$ & $* *$ & $* *$ & $* *$ \\
\hline \multicolumn{5}{|l|}{ Flock age } \\
\hline Old 50 wk & $3.0 \pm 0.71$ & $0.86 \pm 012 b$ & $75.45 \pm 10.91$ & $80.78 \pm 11.22$ \\
\hline Young $35 \mathrm{wk}$ & $1.82 \pm 0.26$ & $1.16 \pm 0.16 \mathrm{a}$ & $105.05 \pm 12.79$ & $112.11 \pm 14.1$ \\
\hline Sig & $*$ & $*$ & $*$ & * \\
\hline \multicolumn{5}{|l|}{ Interaction } \\
\hline $\mathrm{TW} \times$ old & $4.00 \pm 1.40 \mathrm{a}$ & $0.61 \pm 0.09 \mathrm{~b}$ & $51.7 \pm 9.75 b$ & $55.85 \pm 9.94 \mathrm{~b}$ \\
\hline $\mathrm{TW} \times$ young & $2.20 \pm 0.49 \mathrm{ab}$ & $0.94 \pm 0.16 \mathrm{ab}$ & $82.81 \pm 15.11 \mathrm{ab}$ & $89.92 \pm 15.73 \mathrm{ab}$ \\
\hline MFW $\times$ old & $2.29 \pm 0.87 \mathrm{ab}$ & $1.11 \pm 0.14 \mathrm{ab}$ & $99.20 \pm 12.59 \mathrm{a}$ & $105.71 \pm 12.51 \mathrm{a}$ \\
\hline MFW $\times$ young & $1.50 \pm 0.22 \mathrm{~b}$ & $1.35 \pm 0.21 \mathrm{a}$ & $124.62 \pm 17.22 \mathrm{a}$ & $130.60 \pm 20.32 a$ \\
\hline Sig & $*$ & $*$ & $*$ & $*$ \\
\hline
\end{tabular}

${ }^{a, b, c}$ Means within the same column in the same trait with different superscripts are significantly different $(\mathrm{P} \leq 0.05)$.

Table 4. Effect of magnetic water treatment, flock age and their interactions on some egg quality traits of Silver Sabahia strain.

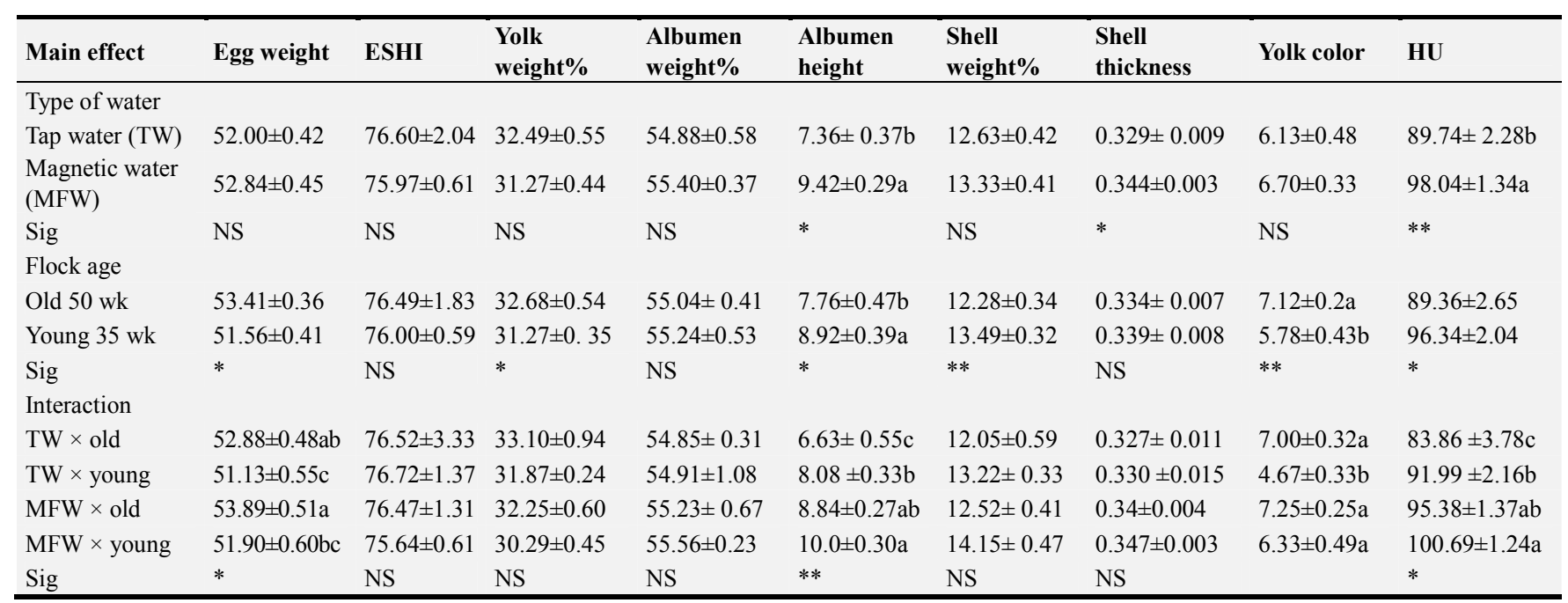

${ }^{a, b, c}$ Means within the same column in the same trait with different superscripts are significantly different $(\mathrm{P} \leq 0.05)$.

Table 5. Effect of magnetic water treatment, flock age and their interactions on fertility percentage and some hatchability traits of Silver Sabahia strain.

\begin{tabular}{|c|c|c|c|c|c|c|c|c|}
\hline \multirow[b]{2}{*}{ Main effect } & \multirow{2}{*}{$\begin{array}{l}\text { Egg weight } \\
\text { loss }(0-19)\end{array}$} & \multicolumn{4}{|c|}{ Embryonic mortality } & \multirow[b]{2}{*}{ Fertility\% } & \multicolumn{2}{|l|}{ Hatchability\% } \\
\hline & & $\begin{array}{l}\text { Early (1- } \\
7 \text { days) }\end{array}$ & $\begin{array}{l}\text { Mid (8-14 } \\
\text { days) }\end{array}$ & $\begin{array}{l}\text { Late (15-20 } \\
\text { days) }\end{array}$ & $\begin{array}{l}\text { Total (1- } \\
\text { 20days) }\end{array}$ & & of fertile eggs & of total eggs \\
\hline Tap water (TW) & $8.56 \pm 0.34$ & $2.84 \pm 0.80$ & $4.40 \pm 0.93$ & $12.19 \pm 2.25$ & $19.43 \pm 2.13$ & $90.72 \pm 0.79$ & $80.56 \pm 291$ & $74.88 \pm 2.55$ \\
\hline Magnetic water (MFW) & $8.26 \pm 0.91$ & $2.56 \pm 0.57$ & $2.37 \pm 0.67$ & $7.97 \pm 1.48$ & $12.96 \pm 2.50$ & $94.77 \pm 0.46$ & $87.1 \pm 2.30$ & $80.28 \pm 2.71$ \\
\hline Sig & & Ns & Ns & Ns & $*$ & $* *$ & $*$ & $*$ \\
\hline Old $50 \mathrm{wk}$ & $8.87 \pm 0.72$ & $2.78 \pm 0.60$ & $3.88 \pm 1.00$ & $11.0 \pm 2.13$ & $17.66 \pm 3.22$ & $91.58 \pm 0.94$ & $82.34 \pm 2.96$ & $76.63 \pm 3.01$ \\
\hline Young $35 \mathrm{wk}$ & $7.96 \pm 0.60$ & $2.59 \pm 0.80$ & $2.73 \pm 0.60$ & $8.83 \pm 1.74$ & $14.15 \pm 2.99$ & $93.92 \pm 0.50$ & $85.85 \pm 2.47$ & $7853 \pm 2.76$ \\
\hline Sig & & Ns & Ns & Ns & $*$ & $* *$ & Ns & $*$ \\
\hline $\mathrm{TW} \times$ old & $8.22 \pm 0.41$ & $3.38 \pm 1.15$ & $5.40 \pm 1.48$ & $12.71 \pm 3.89$ & $21.49 \pm 4.63 \mathrm{a}$ & $89.31 \pm 1.4 \mathrm{c}$ & $78.52 \pm 4.49$ & $72.55 \pm 4.51 \mathrm{c}$ \\
\hline $\mathrm{TW} \times$ young & $8.91 \pm 0.54$ & $2.17 \pm 1.30$ & $3.16 \pm 0.77$ & $11.55 \pm 2.25$ & $16.88 \pm 3.25 b$ & $92.13 \pm 0.36 \mathrm{~b}$ & $83.12 \pm 2.64$ & $77.21 \pm 2.5 b$ \\
\hline MFW $\times$ old & $9.52 \pm 1.40$ & $2.18 \pm 0.34$ & $2.36 \pm 1.07$ & $9.30 \pm 1.95$ & $13.84 \pm 2.84 \mathrm{bc}$ & $93.84 \pm 0.69 \mathrm{ab}$ & $86.16 \pm 2.88$ & $80.71 \pm 3.15 \mathrm{a}$ \\
\hline MFW $\times$ young & $7.00 \pm 0.77$ & $2.93 \pm 1.12$ & $2.38 \pm 0.94$ & $6.65 \pm 2.29$ & $11.96 \pm 3.10 \mathrm{c}$ & $95.70 \pm 0.45 \mathrm{a}$ & $88.04 \pm 3.88$ & $79.85 \pm 4.76 \mathrm{a}$ \\
\hline Sig & & Ns & Ns & Ns & $*$ & $*$ & Ns & $*$ \\
\hline
\end{tabular}

${ }^{a, b, c}$ Means within the same column in the same trait with different superscripts are significantly different $(\mathrm{P} \leq 0.05)$. 
Table 6. Effect of magnetic water treatment, flock age and their interactions on embryo, yolk sac \% at 14, 18 and 21 days of incubation and baby chicks body weight and length for Silver Sabahia strain.

\begin{tabular}{|c|c|c|c|c|c|c|c|}
\hline \multirow{2}{*}{ Main effect } & \multicolumn{2}{|c|}{ Embryo body weight (Free from yolk) } & \multirow{2}{*}{$\begin{array}{l}\text { Baby Chick } \\
\text { body weight (g) }\end{array}$} & \multicolumn{3}{|l|}{ Yolk sac\% } & \multirow[t]{2}{*}{ Chick length (cm) } \\
\hline & $14 d$ & 18d & & 14d & 18d & 21d & \\
\hline \multicolumn{8}{|l|}{ Type of water } \\
\hline Tap water (TW) & $12.5 \pm 0.26$ & $23.01 \pm 0.71$ & $36.13 \pm 0.55$ & $52.49 \pm 2.32 \mathrm{a}$ & $35.56 \pm 1.69 \mathrm{a}$ & $13.0 \pm 1.75$ & $17.46 \pm 0.42 b$ \\
\hline Magnetic water (MFW) & $13.06 \pm 0.34$ & $23.24 \pm 0.42$ & $38.16 \pm 0.67$ & $49.65 \pm 1.24 \mathrm{~b}$ & $33.41 \pm 1.24 b$ & $10.46 \pm 0.81$ & $18.6 \pm 0.51 \mathrm{a}$ \\
\hline Sig & NS & NS & $*$ & * & * & $*$ & $*$ \\
\hline \multicolumn{8}{|l|}{ Flock age } \\
\hline Old $50 \mathrm{wk}$ & $13.34 \pm 0.32$ & $23.45 \pm 0.52$ & $38.18 \pm 0.74$ & $52.04 \pm 1.18$ & $35.6 \pm 1.51 \mathrm{a}$ & 12. $51 \pm 1.22$ & $18.5 \pm 0.22 \mathrm{a}$ \\
\hline Young $35 \mathrm{wk}$ & $12.30 \pm 0.24$ & $22.93 \pm 0.52$ & $36.33 \pm 0.52$ & $50.10 \pm 2.50$ & $32.87 \pm 130 \mathrm{~b}$ & $10.78 \pm 1.21$ & $17.52 \pm 0.60 \mathrm{~b}$ \\
\hline Sig & $*$ & NS & * & * & * & NS & $*$ \\
\hline \multicolumn{8}{|l|}{ Interaction } \\
\hline $\mathrm{TW} \times$ old & $13.18 \pm 0.54$ & $23.3 \pm 0.80$ & $36.88 \pm 0.88$ & $53.61 \pm 1.65 \mathrm{a}$ & $36.69 \pm 2.19 \mathrm{a}$ & $14.262 .45 \mathrm{a}$ & $18.33 \pm 0.33$ \\
\hline $\mathrm{TW} \times$ young & $12.16 \pm 0.18$ & $22.67 \pm 1.20$ & $35.38 \pm 0.63$ & $51.37 \pm 2.05 b$ & $34.4 \pm 2.70 \mathrm{~b}$ & $10.80 \pm 2.15 b$ & $16.63 \pm 0.38$ \\
\hline MFW $\times$ old & $13.45 \pm 0.41$ & $23.70 \pm 0.72$ & $39.33 \pm 1.07$ & $50.46 \pm 2.79 \mathrm{~b}$ & $34.95 \pm 2.10 \mathrm{~b}$ & $10.76 \pm 1.58 \mathrm{~b}$ & $18.67 \pm 0.33$ \\
\hline MFW $\times$ young & $12.57 \pm 0.53$ & $23.18 \pm 0.52$ & $37.1 \pm 0.74$ & $48.83 \pm 1.0 \mathrm{c}$ & $32.02 \pm 1.40 \mathrm{c}$ & $10.16 \pm 0.97 \mathrm{~b}$ & $18.50 \pm 1.50$ \\
\hline Sig & NS & NS & NS & $*$ & $*$ & $*$ & NS \\
\hline
\end{tabular}

a,b,c Means within the same column in the same trait with different superscripts are significantly different $(\mathrm{P} \leq 0.05)$.

Table 7. Effect of magnetic water treatment, flock age and their interactions on egg shell weight and thickens at 14 days and 18 days of incubation for Silver Sabahia strain.

\begin{tabular}{|c|c|c|c|c|}
\hline \multirow{2}{*}{ Main effect } & \multicolumn{2}{|c|}{ Egg shell Weight (g) } & \multicolumn{2}{|c|}{ Egg Shell Thickens (mm) } \\
\hline & 14d & 18d & $14 d$ & 18d \\
\hline \multicolumn{5}{|l|}{ Type of water } \\
\hline Tap water (TW) & $6.50 \pm 0.24$ & $5.92 \pm 0.29$ & $0.349 \pm 0.004 \mathrm{a}$ & $0.293 \pm 0.013$ \\
\hline Magnetic water (MFW) & $6.13 \pm 0.15$ & $5.52 \pm 0.24$ & $0.309 \pm 0.001 \mathrm{~b}$ & $0.276 \pm 0.006$ \\
\hline Sig & NS & NS & $*$ & NS \\
\hline \multicolumn{5}{|l|}{ Flock age } \\
\hline Old $50 \mathrm{wk}$ & $6.00 \pm 0.17$ & $5.67 \pm 0.28$ & $0.331 \pm 0.007$ & $0.268 \pm 0.010$ \\
\hline Young $35 \mathrm{wk}$ & $6.59 \pm 0.211$ & $5.77 \pm 0.25$ & $0.349 \pm 0.013$ & $0.301 \pm 0.007$ \\
\hline Sig & $*$ & NS & NS & NS \\
\hline \multicolumn{5}{|l|}{ Interaction } \\
\hline $\mathrm{TW} \times$ old & $6.00 \pm 0.26$ & $5.56 \pm 0.50$ & $0.346 \pm 0.004$ & $0.283 \pm 0.008$ \\
\hline $\mathrm{TW} \times$ young & $6.80 \pm 0.33$ & $6.28 \pm 0.21$ & $0.353 \pm 0.009$ & $0.303 \pm 0.010$ \\
\hline MFW $\times$ old & $6.00 \pm 0.24$ & $5.78 \pm 0.36$ & $0.305 \pm 0.015$ & $0.253 \pm 0.007$ \\
\hline MFW $\times$ young & $6.29 \pm 0.18$ & $5.25 \pm 0.34$ & $0.315 \pm 0.010$ & $0.299 \pm 0.010$ \\
\hline Sig & NS & NS & NS & NS \\
\hline
\end{tabular}

a,b,c Means within the same column in the same trait with different superscripts are significantly different $(\mathrm{P} \leq 0.05)$.

Table 8. Effect of magnetic water treatment, flock age and their interactions on some relative internal organs at hatched for Silver Sabahia strain.

\begin{tabular}{llllll}
\hline Main effect & Stw\% & Glw\% & Hw\% & Lw\% & Inw\% \\
\hline Type of water & & & & & \\
Tap water (TW) & $4.89 \pm 0.17$ & $0.42 \pm 0.08$ & $0.62 \pm 0.024$ & $2.76 \pm 0.08$ & $3.78 \pm 0.20$ \\
Magnetic water (MFW) & $4.68 \pm 0.14$ & $0.47 \pm 0.07$ & $0.69 \pm 0.025$ & $2.47 \pm 0.11$ & $3.71 \pm 0.21$ \\
Sig & NS & NS & $*$ & NS & NS \\
Flock age & & & & \\
Old 50 wk & $4.83 \pm 0.18$ & $0.57 \pm 0.11$ & $0.63 \pm 0.03$ & $2.56 \pm 0.17$ & $3.45 \pm 0.24$ \\
Young 35 wk & $4.74 \pm 0.14$ & $0.38 \pm 0.05$ & $0.68 \pm 0.29$ & $2.56 \pm 0.08$ & $3.89 \pm 0.18$ \\
Sig & NS & NS & NS & NS & NS \\
Interaction & & & & $2.73 \pm 0.15$ & \\
TW $\times$ old & $5.12 \pm 0.27$ & $0.55 \pm 0.19$ & $0.58 \pm 0.04$ & $2.64 \pm 0.10$ & $3.66 \pm 0.18$ \\
TW $\times$ young & $4.75 \pm 0.21$ & $0.34 \pm 0.06$ & $0.65 \pm 0.03$ & $2.42 \pm 0.28$ & $3.85 \pm 0.31$ \\
MFW $\times$ old & $4.59 \pm 0.21$ & $0.59 \pm 0.16$ & $0.68 \pm 0.03$ & $2.49 \pm 0.11$ & $3.28 \pm 0.42$ \\
MFW $\times$ young & $4.72 \pm 0.19$ & $0.41 \pm 0.08$ & $0.70 \pm 0.04$ & NS \\
Sig & NS & NS & NS & NS \\
\hline
\end{tabular}

${ }^{a, b, c}$ Means within the same column in the same trait with different superscripts are significantly different $(\mathrm{P} \leq 0.05)$. 


\section{Acknowledgements}

We would like to thank Dr. Ahmed Ibrahim, Chairman of the broad of Delta Water Company for his supporting this study and for supplying it with a magnetic water treatment device.

\section{References}

[1] Tabatabaei, S. Chaji. M.; and Mohammadadadi, T. 2010. Correlation between age of rooster and semen quality in Iranian indigenous broiler breeder chickens. Journal of animal and veterinary advances 9 (1): 195-198.

[2] Elibol, O.; and Braket J. 2003. Effect of frequency of turning fromthree to eleven days of incubation on hatchability of broilerhatchingeggs. Poult. Sci., 82: 357-359.

[3] Tona, K.; Onagbesan, O.; DeKetelaere, B.; Decuypere, E.; and Bruggeman, V. 2004. Effect of age of broiler breeders and egg storage on egg quality hatchability, chicks quality, chick weight and chick posthatch growth to forty two days. Appl. Poult. Res., 13: 10-18.

[4] Joseph NS, and Moran Jr ET. 2005. Effect of flock age and postemergent holding in the hatcher on broiler live performanceand further-processing yield. J ApplPoult Res. 14: $512-520$.

[5] Yadgray, L.; Cahaner, A.; kedar O.; and Uni, Z. 2010. Yolk sac nutrient composition and fat uptakein late term embryos in eggs from young and old broiler breeder hens. Poult. Sci., 89: 2441-2452.

[6] Iraqi, Ebtsam, E. E.; Mona M. Ahmed; WesamA. Fares; ElProllosyA. A. and Rizk R. E. 2018. Effect of supplementing the diet with carotenoids enriched spirullina algae 2- on embryogenesis and physiological response for developed chickens. Egypt. Poult. Sci. Vol (38) (II): (657-678).

[7] Iqbal, J.; Khan, S. H.; Mukhtar, N.; Ahmed, T.; and Pasha, R. A. 2016. Effects of egg size (weight) and age on hatchingperformance and chick quality of broiler breeder. J. Anim. Res., 44: 54-64.

[8] Attia, Y. A.; Abd El-Hamid, A.; El-Hanoun, A, M.; Al-Harthe, M. A.; Abdel-Rahman, G. M.; and Abdella, M. M. 2015. Response of the fertility, semen quality, blood constituents, immunity and antioxidant status of rabbit bucks to type and magnetizing of water. Ann. Anim. Sci., 15: 387-407.

[9] Yacout, M. H.; Hassan, A. A.; Khalel, M. S.; Shwerab, A. M.; and Abdel-Gawad, E. I. 2015. Effect of Magnetic Water on thePerformance of Lactating Goats. J Dairy. Vet. Anim. Res., 2: $39-48$.

[10] Ebrahim, S. A. and Azab, E. A. 2017. Biological effects of magnetic water on human and animals. Biomedical sciences, (3): 78-85.

[11] Wang, Y.; Cha, F.; and Yang, T. 1988. Influence of magnetized water on growth and development and physiological characteristics of fluecuredtobaceo. ActaAgric. Univ. Henanensis., 32: 263-269.

[12] Hassan, S, S., Attia, Y. A., Elsheikh, A. M. H., and Abd Elkader, A. M. 2018. Productive, egg quality and physiological responses of Gimmizah chickens as affected by magnetized water of different strengths. Egyp. poult. Sci., 38: $1(51-64)$.

[13] Al-Daraji, H. J.; and Aziz, A. A. 2008. The use of magnetically treated water for improving semen traits of roosters. Alanbar. J. Vet. Sci., 1: 79-92.

[14] El-hanoun. A. M; WesamM. Fares; Attia, Y. A; and Abdella M. M. 2017. Effect of magnetized well water on blood components, immune indices and semen quality of egyptian male geese. Egypt. Poult. Sci. (37) (1), 91-103.

[15] El-Sabrout, K.; and Hanafy, M. 2017. Effect of magnetized water on productive traits of laying chickens. Anim. Sci., 33: 739-742.

[16] El-Sabry, M. I., Charal, J. W., MeMillin, K. W., Lvergne, T. A. 2018. Dose magnetized drinking water affect productivity and egg quality of layers. Egypt. J. anim. Prod., 55 (2): 117-123.

[17] Aly, O. M.; Abou El-Ghar R. Sh.; Afaf I. EL-Turky, Hanan H. Ghanem; Nawar A. N; and Mahmoud T. H. 2017. Silver Sabahia... A new strain of chickens. Egypt. Poult. Sci. (37) (1), 65-72.

[18] Bratton, R. W.; Foote, K.; and Shipman, K. 1956. Procedure for counting bovine sperm with a heamocytometer and calibration of peration used of photometer to estimate sperm count by optical density. Anim. Breed. Lab. Procedure. No. 40, Cornell Univ. Thaca. N. Y., USA.

[19] SAS, 2004. SAS user guide statistics. Release 9.1 SAS institute INC., eary NC. USA.

[20] Duncan, D. B., 1955. Multiple range and multiple F. Test. Biometrics, 11: 1-24.

[21] Shaban A. E.; and Azab, E. A., 2017. Biological effects of magnetic water on human and animals. Biomed. Sci., 3 (4): 7885 .

[22] Al-Mufarrej, S. A.; Al-Batshan, H. A.; Shalaby, M. I.; and Shafey, T. M., 2005. The effects of magnetically treated water on the performance and immune system of Broiler chickens. Int. J. Poult. Sci., 4 (2): 96-102.

[23] El-Ratel. I. T.; and Sara F. Fouda. 2017. Effect of magnetic water on production and preservation semen of rabbit bucks. Egypt. Poult. Sci. Vol (37) (IV): (1187-1202).

[24] Ghanem, Hanan H; Amany A. ElSahn; Ebtsam E. E. Iraqi and Afaf I. EL-Turky. 2020. Effect of magnetic water and flock age on semen evaluation and hatchability traits in Golden Sabahia strain. Egypt. Poult. Sci., Vol. (40): 421-440.

[25] Silversides, F, G and Scott T. A. 2001. Effect of Storage and layer age on quality of eggs from two lines of hens. Poultry Science 80 (8): 1240-5.

[26] Qiaoxian, Yue ChenHui, XuYingjue, Huang Chenxuan, Xi Jianzhong, Zhou Rongyan, XuLijun, Wang Han, Chen ye. 2020. Effect of housing system and age on products and bone properties of Taihang chickens. Poultry Science 99: 1341-1348.

[27] Al-Nueimi, S. H.; Al-Badry, K. J.; Atteyh, A. J.; Alsabea, W. S.; Ibrahim, F. F.; and Rajab, B. 2015. Effect of magnetic water drinking on testis dimension, scrotal circumference and blood parameters of Holstein bulls bron in Iraq. Adv. Anim. Vet. Sci., 3: 413-417. 
[28] Ahmed Mona R. M.; Wesam A. Fares; Rizk R. E.; and Abdalla E. A. 2016. Skeletal embryonic development and hatching traits affected by eggshell osteropontin protein during two stage of egg laying cycle. Egypt. Poult. Sci. (36), 805-823.

[29] El-Hanoun, A. 2014. Effect of magnetic treated water on some productive and reproductive performance in Egyptian gees. 7th International Poult. Conf. Proceeding, NovAin El Sukhna. Red Sea Egypt, 93-103.

[30] El-Sahn, Amany, A.; Rizk R. E. and Khalifah, M. M. 2013. Improving the cold resistance of chicks through al tering the thermoregulatory memory 1- During the last phase of embryogenesis. Egypt. Poult. Sci. Vol 33 (577-592).
[31] Shinder, D.; Rusal, M.; Giloh, M.; and Yahav, S. 2009. Effect of repetivie acute cold exprsures during the last phase of broiler embryogenesis on cold resistance through the life span. poul. Sci. 88: 636-646.

[32] Al-Fadul, M. F. M. 2006. The effect of magnetically treated water and diet on the performance of the broiler chicks. MSC. in Poultry Production, Fac. Anim. Prod., University of Khartoum, Sudan.

[33] Molenaar, R., Hulet, R.; Meijerhof, R.; Maatjens, C.; Kemp, B.; and Van Den Brand, H., 2011. High egg shell temperatures during incubation decrease growth performance and increase the incidence of ascites in broiler chickens Poult. Sci. 90: 624632 . 